\title{
BABIES BORN UNDER 1000 GRAMS - PERINATAL OUTCOME; AN INSTITUTIONAL EXPERIENCE
}

\author{
J. Alallah, M. Al-Qurashi, S. Elbeely, A. Moustafa, A. Musba, E. Hanafi \\ Section of Neonatology, Department of Pediatrics, King Abdulaziz Medical City, Jeddah, Saudi Arabia
}

Background: Survival of extreme-low-birth-weight (ELBW) infants has improved remarkably in the last decade. Still there is Paucity in reporting survival rate of ELBW infants from underdeveloped countries especially Saudi Arabia.

Objective: To describe the current survival and neonatal morbidities among (ELBW) infants in single centre WR.

Methods: Records of all ELBW admitted to NICU, at King Abdulaziz Medical City, WR from Jan2007 to Dec2010, were collected, survival and neonatal morbidities were analyzed by two categories of birth weight (501-750 $\mathrm{g}$ and $751-1000 \mathrm{~g})$.

Result: Sixty ELBW infants were included. Forty one (68\%) babies survived till hospital discharge. Twenty two babies 500-750 grams and thirty eight babies in 751-1000. Survival rate increased from $45 \%$ for the 501-750 g neonates from $82 \%$ for the 751 -1000 gram. Group one (BW500-750g) were more likely to have RDS required intubation and surfactant $100 \%$ Vs $90 \%$, unlikely to be extubated by $48 \mathrm{hrs}$ of life $40 \%$ vs $86 \%$. incidence of BPD ( $30 \%$ Vs 6\%), NEC 20\% Vs $0 \%$ ) sever ROP $30 \%$ Vs $3 \%$ ) and late onset sepsis ( $70 \%$ Vs $52 \%$ ) . none of the group 1 had grade 3 or $4(\mathrm{IVH})$ or(PVL) Vs $3 \%$ in the group 2.

Conclusion: There is a significant decrease in mortality and neonatal morbidities observed among the different birth weight groups. Birth weight has a significant impact on survival.To our knowledge, this is the first study that reports the survival rates in babies less than $1000 \mathrm{gm}$ in Western region SA. 